\title{
Membrane Fouling Characterization by Infrared Thermography
}

\author{
Kennethrex O. Ndukaife ${ }^{1,2}$, Justus C. Ndukaife ${ }^{2,4}$, A.G Agwu Nnanna ${ }^{2,3}$ \\ ${ }^{1}$ Department of Electrical/Computer Engineering, Purdue University, Calumet, $2200169^{\text {th }} \mathrm{St}$, \\ Hammond, IN 46323, USA \\ ${ }^{2}$ Water Institute, Purdue University, Calumet, $2200169^{\text {th }}$ St, Hammond IN, 46323, USA \\ ${ }^{3}$ Department of Mechanical Engineering, Purdue University, Calumet, $2200169^{\text {th }}$ St, Hammond, \\ IN 46323, USA \\ ${ }^{4}$ School of Electrical/Computer Engineering Purdue University, West Lafayette IN 47907-2035, \\ USA
}

Corresponding author's email: kennethrex2012@gmail.com

\begin{abstract}
An Infrared thermography (IRT) technique for characterization of fouling on flat sheet membrane surface has been developed. In this work, an IR camera was used to measure surface temperature and emissivity of foulant on a membrane surface. Different fouling experiments were performed using different feed concentrations of aluminum oxide nanoparticle mixed with deionized water so as to investigate the effect of feed concentration on the degree of fouling and on the emissivity values measured on the membrane surfaces. Our findings revealed that the emissivity of the fouled membrane surface is contingent on the surface roughness as well as the material composition of the foulant. The technique was utilized to distinguish between foulants made of metallic materials from those that are non-metallic. This approach, which is simple to use and nondestructive represents an important addition to the toolset of fouling analysis techniques and would benefit a wide range of applications from observation of foulalnt structure to qualitative assessment of composition of foulant material.
\end{abstract} Keywords: Emissivity; Infrared camera; Membrane fouling; Temperature; Thermography; Ultrafiltration.

\section{INTRODUCTION}

Fouling is a major issue limiting the widespread use of the membrane technology in the industrial world [1][2]. Severe fouling may require intense chemical cleaning or membrane replacement and this thus increases the operating cost of a treatment plant. Membrane fouling is a very complicated phenomenon due to the wide variety of foulants encountered in practice. Flux-decline data are usually used to explain fouling and predict the mechanism of fouling. However, the values of flux decline obtained by traditional experimental methods are not necessarily reliable because concentration polarization, membrane compaction and degradation may occur simultaneously with fouling [3][4]. Efforts towards understanding the phenomenon and evolution of fouling have been studied by numerous researchers as reported in the review article [5]. The scanning electron 
microscope (SEM) represents one of the means for membrane fouling characterization. Other methods include but are not limited to the following; visual observation, optical microscopy (OM), ion chromatography (IC), Xray fluorescence $(\mathrm{XRF})$, inductively coupled plasma optical emission spectrometry (ICP-OES), Fourier transform infrared spectroscopy (FTIR), X-ray diffraction (XRD), atomic absorption spectroscopy (AAS) [1]. The SEM is attractive because it can generate images with high spatial resolution. It has been used by several researchers for the structural examination and analysis of fouling layer with high precision ranging from micrometer to the nanoscale regime [6][7][8]. High resolution SEM images can reveal the structural morphology such as shape and size of the fouling layer. Lee et al [9] and Fan et al [10] employed the SEM to describe the structure of dynamic membranes resulting from sludge flocs. Tian et al [11] used the SEM to investigate the effectiveness of various membrane cleaning methods. While the SEM is a proven and wellestablished technology for the characterization of fouled membranes, it has several drawbacks which includes the requirement for pretreatment protocols of samples (such as sample dehydration and gold coating for nonconducting samples), high purchasing and maintenance cost, mutilation of the membrane, requires some level of training before one can operate it and it occupies an appreciable amount of space. Efforts towards developing new techniques for fouling characterization that overcomes some of the drawbacks listed above are thus sought for.

Over the years, researchers have employed the capabilities of the IRT technique in engineering applications such as monitoring of electronic printed circuit boards (PCBs) [12][13], thermal inspection of electrical equipment [14][15], evaluation of stress fatigue damages in materials [16][17][18], observation of plastic deformations [19], monitoring, of tensile deformation [20][21][22], heat losses in buildings [23][24][25], inspection of heavy machineries [26] and inspection of welding [27][28][29]. To the authors' knowledge, no prior work has reported the use of the IRT for membrane fouling characterization. This work aims at addressing some of the issues associated with the use of the SEM and other characterization techniques and also adds to the number of existing membrane characterization techniques. We have therefore developed in this work a novel non-invasive technique for fouled membrane characterization using the principle of infrared thermography in a continuous thermal excitation mode. This method employs the use of an infrared camera to obtain infrared images due to IR radiations emanating from the fouled membrane surface upon continuous thermal excitation. Our findings showed that the fouled layer emissivity is a function of the surface roughness as well as elemental composition of the foulant. We showed the ability to discriminate between foulants that have metallic properties from those that are non-metallic. Energy Dispersive X-ray spectroscopy was used to validate the result. The approach reported here is low-cost compared to the SEM, easy to use, fast and occupies little space, nondestructive, while enabling the ability to monitor the development and progression of fouling throughout the entire membrane.

\section{THEORY}

The infrared camera detects radiations emanating from the membrane surface and records these radiations in the form of temperature measurements. According to Marinetti Sergio, and Pier Giorgio Cesaratto, every body at a temperature $T$ above absolute zero emits radiation, and the spectral blackbody emissive power, $P_{\lambda, b b}(T)$ at a given wavelength $\lambda$ is given by the Planck's law [30].

The sensed blackbody emissive power $S_{b b}(T)$ received by the Infrared camera detector with a spectral response $R(\lambda)$ and wavelength detection range of $7.5-13 \mu \mathrm{m}$ is expressed by eqn. (i).

$S_{b b}(T)=\int P_{\lambda, b b}(T) \cdot R(\lambda) \cdot d \lambda$

The spectral response $R(\lambda)$ (see figure S3 in the supporting information) is specific to the camera detector used for the experiment. This information is provided by the manufacturer usually in the form of a plot over the operating wavelength of the detector and a curve-fitting software is required to extract the equation for the spectral response $R(\lambda)$ for calculation purposes. 
The total signal $S_{c}$ captured by the IR camera lens is a representation from three different sources namely:

1) Emission from the surface $=\varepsilon\left(T_{t}\right) \cdot \tau \cdot S_{m s}$, where $\varepsilon$ is the emissivity of the membrane surface with fouling deposits and $\tau$ is the transmittance of the atmosphere, $S_{m s}$ is the power radiated from the membrane surface

2) Reflected emission from surrounding $=\left(1-\varepsilon\left(T_{t}\right)\right) \cdot \tau \cdot S_{\text {surr }}$, where $(1-\varepsilon)$ is the reflectance of the object, $S_{\text {surr }}$ is the power radiated from the surrounding.

3) Emission from the atmosphere $=(1-\tau) \cdot S_{a t m},(1-\tau)$ is the emissivity of the atmosphere, $S_{a t m}$ is the power radiated from the atmosphere.

Combining the three signals received by the IR camera detector, we can obtain an expression for the total radiation power captured by the camera:

$$
\begin{aligned}
S_{c} & =\varepsilon\left(T_{t}\right) \cdot \tau \cdot S_{m s}+\left(1-\varepsilon\left(T_{t}\right)\right) \cdot \tau \cdot S_{\text {surr }}+(1-\tau) \cdot S_{a t m} \\
& =\tau\left[\varepsilon\left(T_{t}\right) \cdot S_{m s}+\left(1-\varepsilon\left(T_{t}\right)\right) \cdot S_{\text {surr }}\right]+(1-\tau) \cdot S_{a t m} \\
& =\tau \cdot S_{e q}+(1-\tau) \cdot S_{a t m} \\
S_{e q} & =\varepsilon\left(T_{t}\right) S_{m s}+\left(1-\varepsilon\left(T_{t}\right)\right) S_{\text {surr }}
\end{aligned}
$$

The equations above give us an insight on how the IR camera receives and records radiation captured from the membrane surface under investigation. It reveals that the equivalent signal captured by the IR camera is a function of the emissivity of the surface, target temperature, power radiated from the membrane surface and the effect of the surrounding medium. The power radiated from the surface is affected by several parameters such as the nature of the surface, energy supplied to the surface and so on.

\section{MATERIAL AND METHODS Ultrafiltration (UF) and Infrared Thermography system}

The main considerations in choosing an appropriate UF system include industrial relevance and wastewaterdisposal problems. Aluminum oxide nanoparticles partially soluble in water was suspended in distilled water and used as the feed solution for the filtration experiment. The experimental conditions and parameters are summarized in Table 1. Flat-sheet thin film polymer composite membranes (GE Osmonics) with a molecular weight cut-off (MWCO) between 150-300 and typical flux of 31 GFD/100 psi were prepared and used in all the fouling experiments. In order to monitor and determine the onset and progression of fouling on a membrane surface, a flat sheet crossflow cell made of delrin acetal material (Sterlitech Corporation) with an effective membrane area of $42 \mathrm{~cm}^{2}$ flow channel was used. The two cell components are assembled using the stainless steel studs as guides and also using the "quick-release" hand nuts to tighten the components together.

Figure 1 is a schematic representation of the UF membrane filtration system. The UF system allows for the control of inlet pressure and the retentate flow rate. The infrared thermography system consists of a camera and a heat source (Thermoscientific cimarec hotplate). The measurements were performed with a FLIR A320 camera operating in the spectral range of 7.5-13 $\mu \mathrm{m}$, with a focal plane array (FPA), uncooled microbolometer detector which has a detector pitch of $25 \mu \mathrm{m}$ which enabled tight focusing over the membrane surface and a $320 \times 240$ pixel image resolution format. The object temperature range of the camera was set to $(-20$ to +120$){ }^{\circ} \mathrm{C}$. The system was mounted on a Thorlabs translational stage for easy focusing of the infrared camera over the flat sheet membrane surface and a standby computer was used for real-time collection of data. In order to accurately measure the emissivity, the temperature on the surface of the membrane has to be determined correctly. To do 
this, we ensured that the membrane was really dry by introducing a hot plate set at 60 degrees Celsius as a heat source beneath the flat sheet membrane for 60 minutes. Visual inspection also showed that the membrane was dry after this process. At this constant temperature of 60 degrees Celsius, the emissivity at various positions on the membrane surface was determined by following the procedure outlined by the camera's manufacturer in the user's manual.

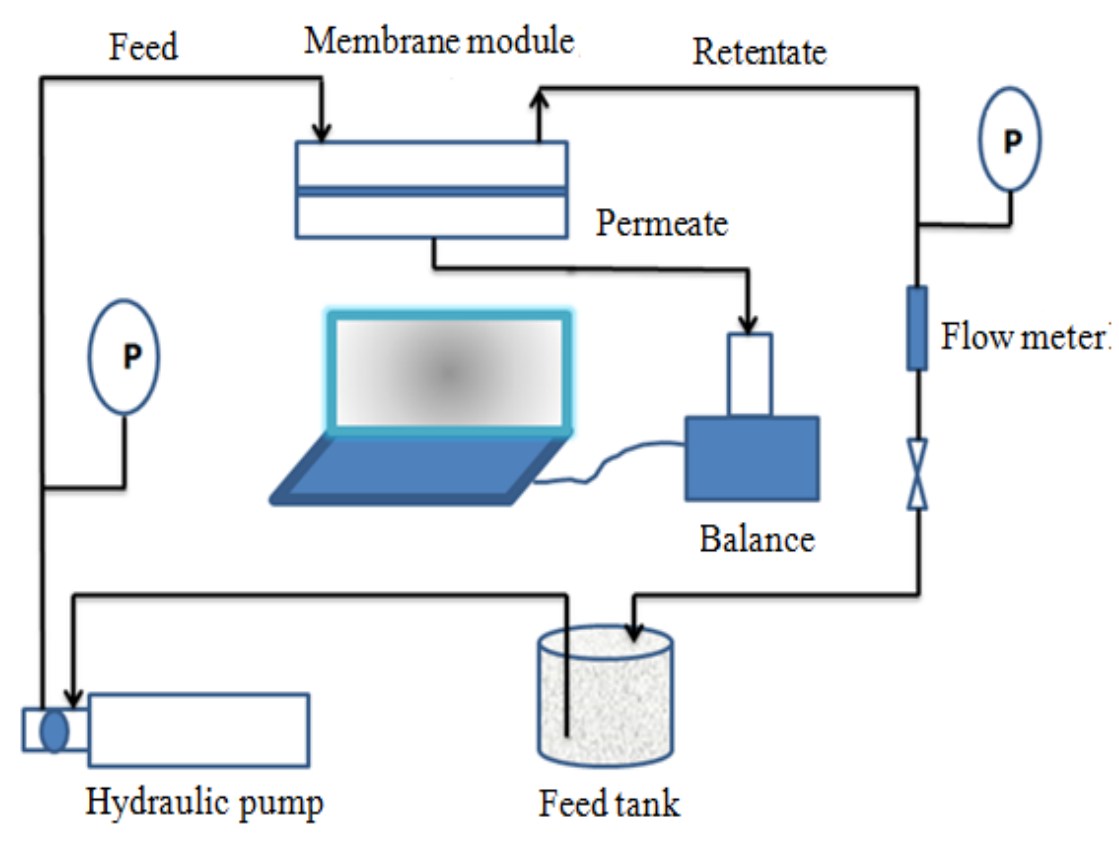

Fig. 1: Schematic of the UF membrane filtration system

\section{Experimental procedure and fouling experiments}

Prior to the fouling experiment, each experiment commenced with DI water being circulated through the system at the desired flow rate and applied pressure for 2 hours as specified by the manufacturer, so as to compress the membrane and to build up a stable flow field. Once steady permeate flux was attained, the feed was switched to the synthetic waste water made of aluminum oxide nanoparticle to initiate the fouling phase in which concentration polarization and fouling occurred.

In each UF experiment, continuous stirring in the feed tank was achieved using PB-700 Jartester at a speed of 300 RPM. The temperature of the feed solution was kept relatively constant; this was observed throughout the experimental duration using a thermometer inserted in the feed tank. During the experiments the retentate was recycled continuously to the feed tank while the permeate flux was measured with a mass balance (AND GX8000) connected to a computer. After duration of four hours of fouling experiment, the filtration was stopped and the flat sheet membrane was removed from the cell and left to dry on the hotplate set at a temperature 60 degrees Celsius before imaging using the infrared camera. The emissivity at various points along the length of the membrane was determined and recorded. Prior to beginning a new experiment, the filtration system was cleaned by recycling $1000 \mathrm{ml}$ of dilute hydrochloric acid for about 5 minutes followed by DI water for another 15 minutes. This ensured that no contaminants were left deposited along the walls of the connecting tubes or membrane module. A new membrane is then inserted into the cell to initiate a new fouling experiment with a different concentration $(333 \mathrm{ppm})$ of the feed solution. The initial preconditioning of the membrane was done by circulating DI water through the system. Once the flux was stabilized after duration of about 90 minutes to 120 minutes, the feed was switched to the fouling solution and filtration continued for another four hour period, after which imaging is done again. This procedure was repeated for experiment using 1833 ppm and 3333 ppm 
of the synthetic waste water and the infrared images, emissivity data of the resulting fouled membrane was obtained too.

\section{Morphological Characterization}

The morphological features of the fouled membrane sample was analyzed for the extent of coverage and spatial distribution of the fouling layer on the membrane surface using the Flir R \& D software.

Table 1: Operating conditions for the fouling experiment

\begin{tabular}{|l|l|}
\hline \multicolumn{1}{|c|}{ Parameters } & \multicolumn{1}{|c|}{ Value } \\
\hline Feed types & $\begin{array}{l}\text { Aluminum Oxide }+ \\
\text { Water, } \\
\text { Aluminum + Water }\end{array}$ \\
\hline Feed Concentration & $\begin{array}{l}333,1833 \quad \& \quad 3333 \\
\text { ppm }\end{array}$ \\
\hline Pressure & $20 \mathrm{psi}$ \\
\hline Temperature & $23 \pm 2^{\circ} \mathrm{C}$ \\
\hline $\begin{array}{l}\text { Operating frequency } \\
\text { of Pump }\end{array}$ & $25 \mathrm{~Hz}$ \\
\hline Speed of stirrer & $300 \pm 10$ RPM \\
\hline $\begin{array}{l}\text { Membrane type } \\
\mathrm{GE} \mathrm{OSMONICS} \\
\mathrm{PVDF} \\
\mathrm{membrane}\end{array}$ \\
\hline $\begin{array}{l}\text { Effective membrane } \\
\text { area }\end{array}$ & $42 \mathrm{~cm}^{2}$ \\
\hline $\begin{array}{l}\text { Duration of } \\
\text { experiment }\end{array}$ & $240 \mathrm{minutes}^{-1}$ \\
\hline
\end{tabular}

\section{RESULTS AND DISCUSSION}

Using the experimental scheme outlined above, the changes in permeate flux of the flat sheet membranes with operation time during the fouling experiments carried out at three different concentrations of the feed solutions are illustrated in figure 2. The plot shows a decline in the permeate flux as filtration progressed. This reduction in flux with time is attributed to the deposition of contaminants (fouling) on the membrane surface which causes blockage of the membrane pores. In order to corroborate the flux decline data, the FLIR A320 infrared camera was used to image the membranes to determine the extent of fouling and the emissivity changes across its entire length. The changes in emissivity across the length of the membrane surface were used for monitoring foulinglayer growth in all the experiments. 

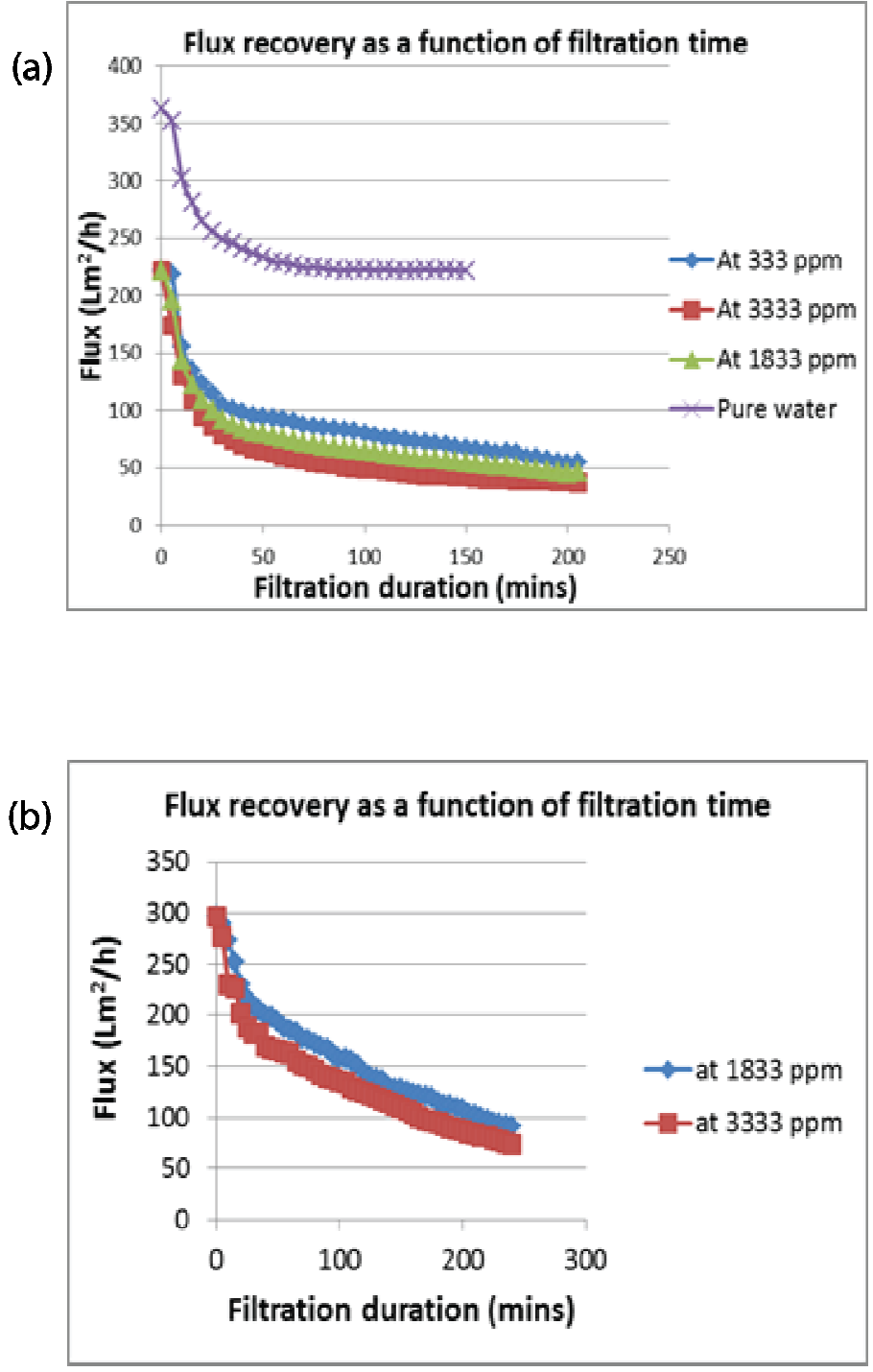

Fig 2: Permeate flux versus filtration duration of the fouling experiments for (a) aluminum oxide, and (b) aluminum particles in deionized water

Figure $2 \mathrm{a}$ shows that with the pure water phase, the permeate flux is not expected to decline. The first 90 minutes of pure water filtration represents the preconditioning phase of the membrane, after which the permeate flux was seen to be stable for the rest of the experiment until 150 minutes before the fouling experiment with the synthetic wastewater was initiated. The figure 2 shows the permeate flux behavior for all feed concentrations investigated with the synthetic wastewater. Although, the trend of the decrease in flux with time is essentially the same for $333 \mathrm{ppm}, 1833 \mathrm{ppm}$ and $3333 \mathrm{ppm}$ feed concentrations, it is seen that for lower concentrations of the synthetic waste water; $333 \mathrm{ppm}$ and $1833 \mathrm{ppm}$ respectively, the change of permeate flux is less significant than at higher concentration; $3333 \mathrm{ppm}$. After a duration of 120 minutes, the permeate flux value obtained for $333 \mathrm{ppm}, 1833 \mathrm{ppm}$ and $3333 \mathrm{ppm}$ were $74.0 \mathrm{l} / \mathrm{m}^{2} \mathrm{~h}, 59.7 \mathrm{l} / \mathrm{m}^{2} \mathrm{~h}$ and $45.43 \mathrm{l} / \mathrm{m}^{2} \mathrm{~h}$ respectively. Comparing figure $2 \mathrm{a}$ to figure $2 \mathrm{~b}$, the slightly different trend of the permeate flux decline can be attributed to the nature and size of the particles used in preparation of the feed solutions for the different experiments. In figure $2 \mathrm{a}$, where aluminum oxide nanoparticles with average particle size of $50 \mathrm{~nm}$ was used, the tendency of pore blockage to occur was significantly very high as the nano-sized particles could potentially get stuck in the membrane pores and that caused a faster rate of flux decline. In figure $2 b$, aluminum micro particles of about 30 $\mu \mathrm{m}$ was used which inferred less likelihood or complete absence of pore blockage, since the larger particles cannot get stuck in the membrane pores rather they can potentially act as a medium for clean water to permeate through, thereby resulting in lower flux decline rate. 


\section{(a) Variation of thickness from Feed to Retentate side}

[333ppm]

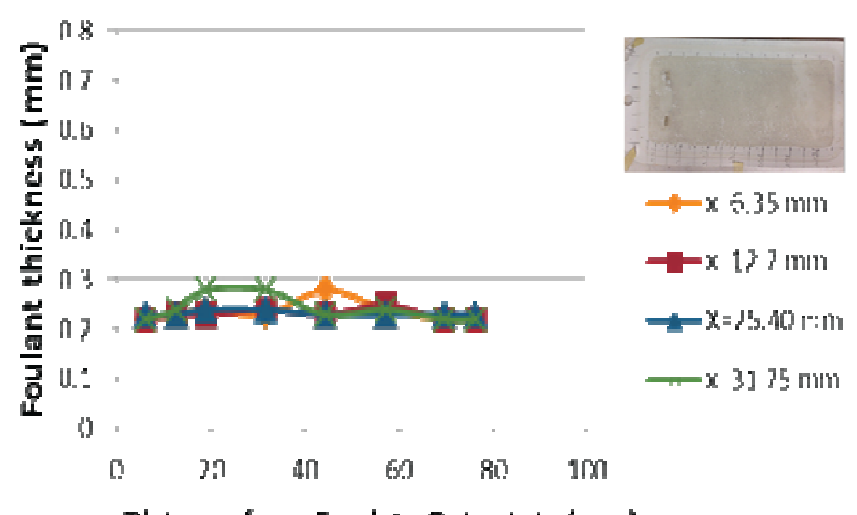

Distance from Feed to Retentate (mm)

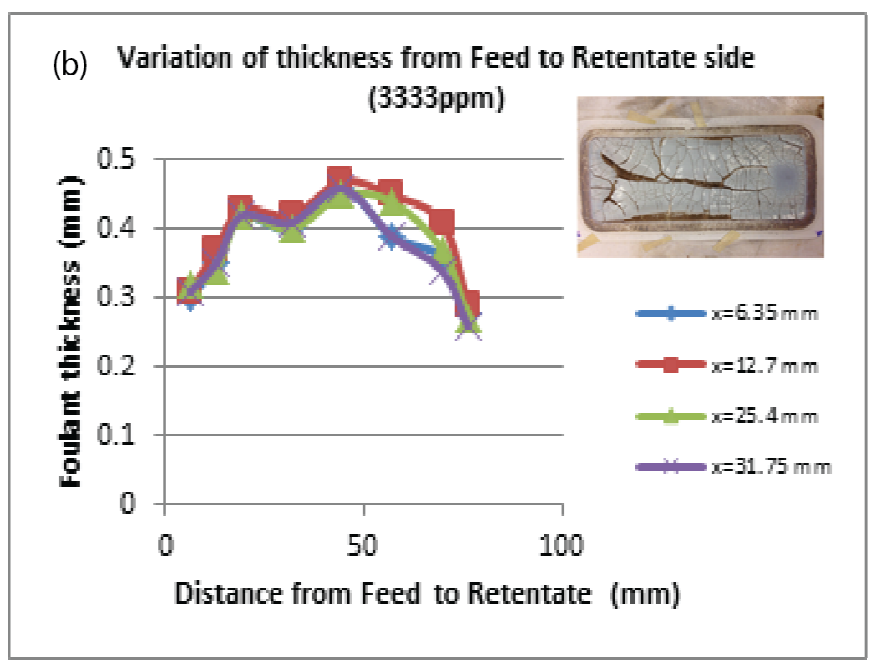

Fig 3: Line plot showing variation of foulant thickness from feed to retentate side for fouled membranes corresponding to (a) $333 \mathrm{ppm}$ and (b) $3333 \mathrm{ppm}$ feed concentrations of aluminum oxide. The insert shows the pictorial views of the fouled membranes at the corresponding feed concentrations

The pictorial view of the resulting fouled membranes at different feed concentrations of the synthetic wastewater is added as an insert alongside the line plots of the variation of foulant thickness from feed to retentate side of the membrane as shown in figure 3 (a) \& (b). It is evident from the image that, at higher feed concentration, a higher deposit of fouling is observed across the membrane surface from the feed side to the retentate side. The residue thickness of the contaminants was measured progressively from one end of the membrane (feed side) to the other end (retentate side) as represented by the $\mathrm{x}$-axis of the line plots. The distance $\mathrm{x}=6.35,12.7,19.05,25.4,31.75 \mathrm{~mm}$ correspond to specific points along the shorter length of the membrane. At each of these points, the variation of thickness from feed to retentate side was measured as portrayed by the four different line plots. 
Figure 3 (a) shows a relatively uniform progression of fouling on the membrane surface with the maximum residue thickness observed to be about $0.28 \mathrm{~mm}$ for feed concentration of $333 \mathrm{ppm}$. This result reveals that at lower concentrations of the feed solutions, the deposition of contaminants as filtration progresses will be relatively uniform. A different pattern was observed (figure 3 (b)) when the feed concentration was increased by 10 times the initial concentration. Fouling was found to be more dominant in the middle section of membrane between $25 \mathrm{~mm}$ to $60 \mathrm{~mm}$ from the feed to the retentate side respectively with peak thickness of about $0.47 \mathrm{~mm}$. The results recorded at these various concentration supports the claims that fouling thickness increases with increasing concentration of feed solution. The results of figure 3 (b) can be attributed to the fact that the inlet section experiences the most pressure compared to the remaining portion as the feed flows across the membrane. As the feed flows tangentially across the membrane, it is assumed that the pressure decreases from the inlet along the length of the membrane.

The pressure at the inlet exerts a lateral force on the suspended particles and acts to propel them forward. This slightly impedes fouling at the inlet section. The central section of the membrane has lower pressure in comparison with the inlet section and hence more fouling is expected. This explains the higher fouling deposit thickness observed on the central section with respect to the inlet section. Now as the central section intercepts first before the outlet section, it is also expected to have more fouling deposit as it is only the particles not stuck on the central portion that would find its way to the outlet section. This observation is also in agreement with the theoretical predictions that suggest that increasing the flow velocity reduces fouling deposition [31].

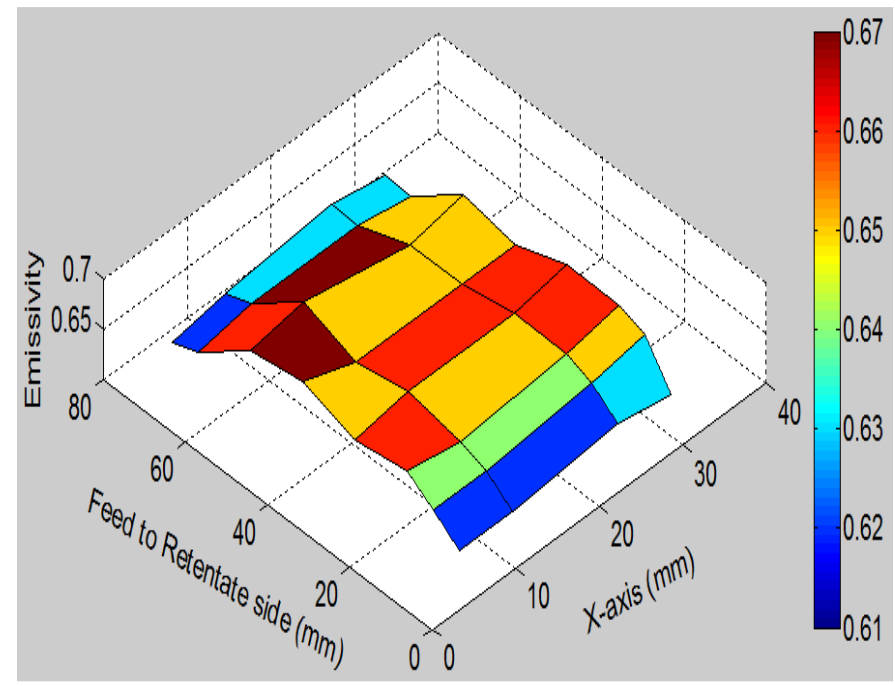

(a) 


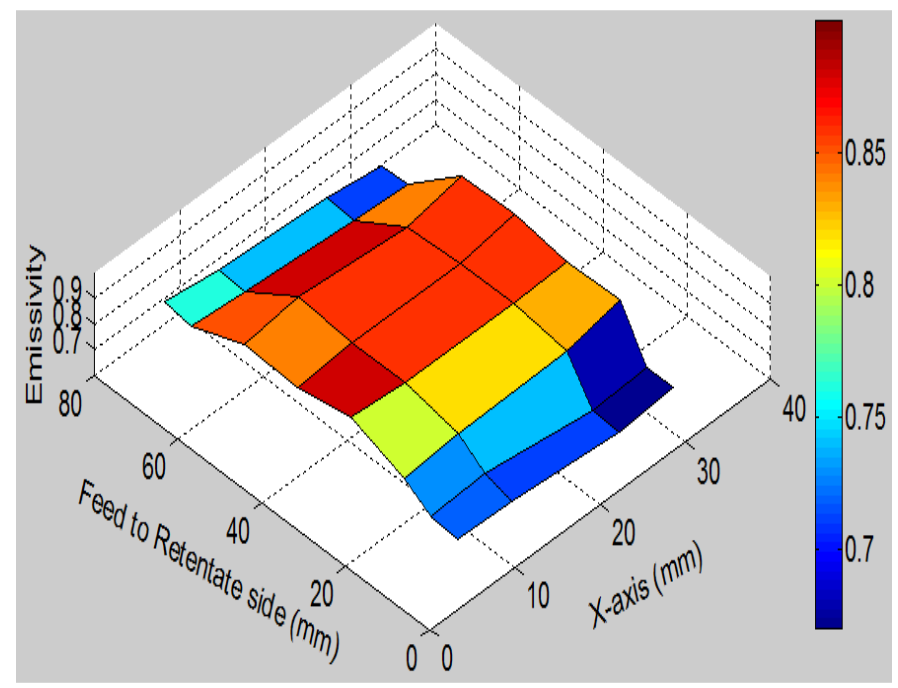

(b)

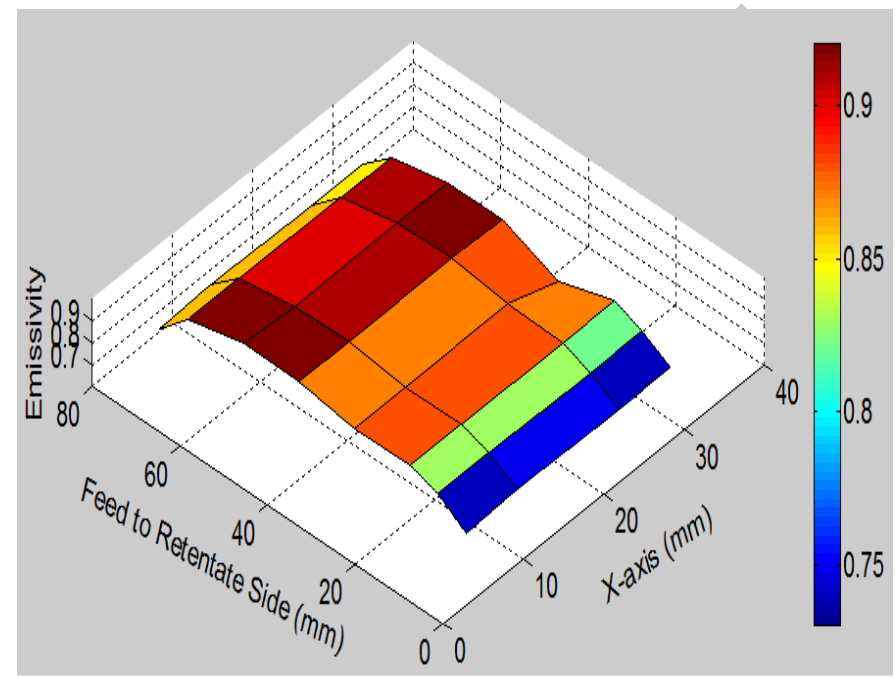

(c)

Fig 4: 3D plots showing emissivity values of various locations of the fouled membranes at feed concentration of (a) 333ppm (b) $1833 \mathrm{ppm}$ and (c) 3333ppm feed concentrations of aluminum oxide.

The average emissivity value for the three feed concentrations $333 \mathrm{ppm}, 1833 \mathrm{ppm}$ and 3333 ppm at various locations across the fouled membrane surface was used to characterize the fouling deposit on the membrane surface as shown in figure 4 (a) to (c). The results reveal that emissivity is a function of feed concentration and surface roughness.

Since the emissivity of a surface also depends on the elemental composition of the surface, experiments were conducted to discriminate between different foulants using the IRT technique. For this experiment, aluminum (Al) particles suspended in deionized water was utilized as another feed solution. Aluminum being metallic is highly reflective at visible and infrared wavelengths, which are well above the plasma wavelength. The high reflectivity corresponds to low absorptivity for a relatively thick substance (where transmissivity is negligible). By virtue of Kirchhoff's Law, under thermal equilibrium, absorptivity is equal to emissivity; thus metallic materials have very low emissivity [32]. On the other hand non-metallic materials usually have high emissivity. To experimentally demonstrate the ability to distinguish between metallic versus non-metallic foulants, experiments were conducted with aluminum (Al) and aluminum oxide $\left(\mathrm{Al}_{2} \mathrm{O}_{3}\right)$ particles in water. During characterization of the fouled membrane resulting from filtration of these two different materials at different 
times by IRT, it was observed that by determining emissivity on the surface of the fouled membranes, one could conclude which of the materials was filtered. This was because the aluminum particles being metallic is reflective in nature and thus have significantly lower emissivity in the range $(0 \leq \varepsilon \leq 0.40)$ in comparison with the aluminum oxide particles which is non-metallic in nature because it is oxidized and thus has emissivity in the range $(0.60 \leq \varepsilon \leq 0.92)$ as depicted in figure 5a and 5c. The energy dispersive $\mathrm{x}$-ray (EDX) analysis using the SEM (JOEL 6010LA) was done for the fouled membrane resulting from the use of aluminum and aluminum oxide as wastewater at $\times 200$ magnification so as to corroborate the claims of the ability of the IRT technique to tell whether a foulant was metallic or non-metallic in nature and the results were compared alongside the 3D emissivity plots resulting from the fouled membranes. Figure $5 \mathrm{~b}$ shows the presence of three elements namely; carbon, aluminum and oxygen with aluminum being more present (percentage mass was 93.92\%), revealing that the membrane was fouled with a wastewater containing aluminum in large quantity and hence the entire membrane surface was covered with aluminum, while figure $5 \mathrm{~d}$ unveils five elements; carbon, oxygen, aluminum, phosphorous and silver. The result reveals aluminum (48.94\%) and oxygen (46.44\%) are almost proportionally the same by mass, hence being dominant, thus predicting aluminum oxide as the main constituent of the synthetic wastewater.
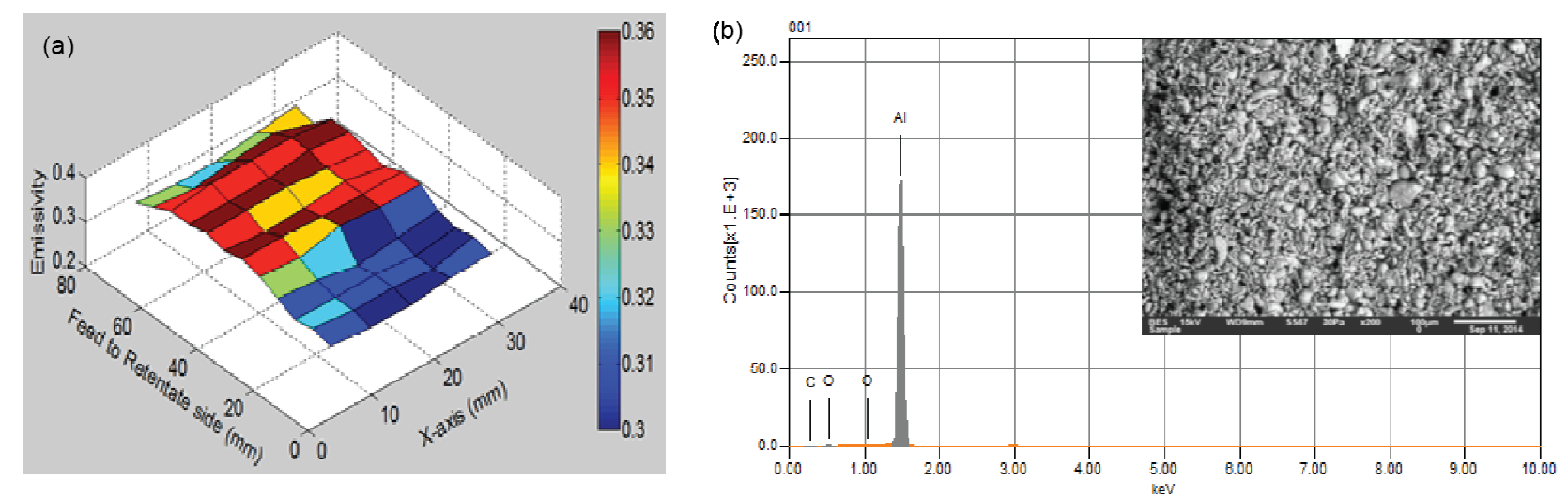

\begin{tabular}{|l|l|l|l|}
\hline Chemical & C & O & Al \\
\hline M ass (\%) & 4.64 & 1.44 & 93.92 \\
\hline
\end{tabular}
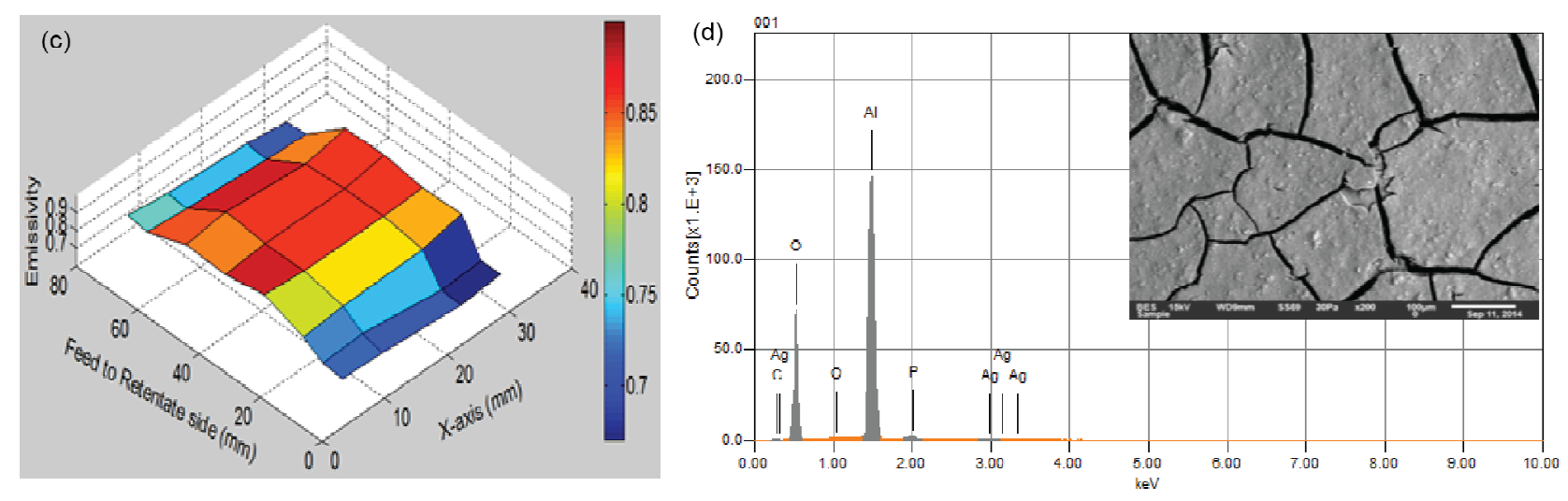

\begin{tabular}{|l|l|l|l|l|l|}
\hline Chemical & C & O & Al & P & Ag \\
\hline M ass (\%) & 2.77 & 46.44 & 48.94 & 0.97 & 0.88 \\
\hline
\end{tabular}

Fig 5: 3D plots showing emissivity values of various locations on the fouled membranes at 1833ppm feed concentrations of the synthetic feed water alongside SEM images and EDX analysis (a-b) aluminum, and (c-d) aluminum oxide. 
Thus emissivity measurement of the foulant layer as demonstrated in this work could be used to yield crucial qualitative information on the nature of the foulant layer material whether it is of metallic or non-metallic nature.

The figure 6 below shows the error bars associated with the measured spectral emissivity values for aluminum and aluminum oxide respectively as compared in figures $5 \mathrm{a}$ and $5 \mathrm{~b}$. The plot in figure 6 shows the case for emissivity measured along the center of the long axis of the membrane. The error bars depict that the changes in emissivity are sufficiently large enough to distinguish between aluminum and aluminum oxide foulants by the IRT approach.

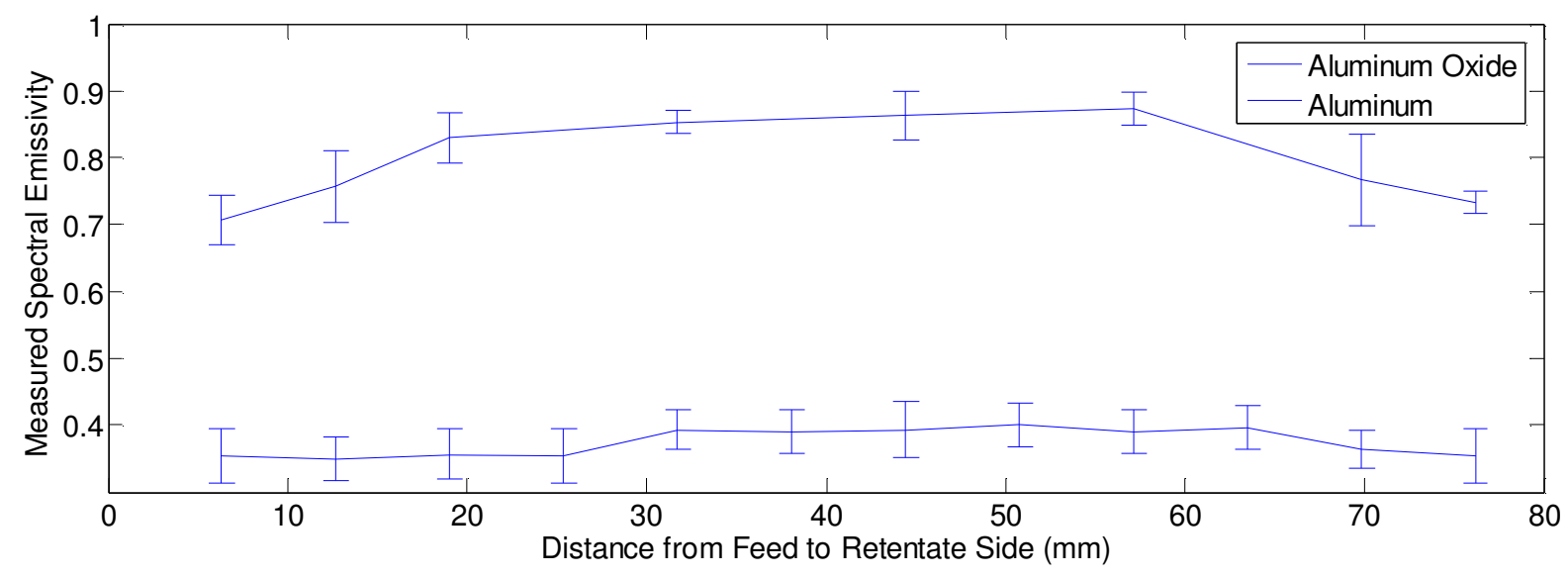

Fig 6: Error bars for measured emissivity for aluminum and aluminum oxide along the center of the long axis of the membrane.

\section{CONCLUSION}

This work reports the first study on membrane fouling characterization by use of infrared thermography approach. Results indicate that the technique is sensitive to changes that occur on the membrane surface due to deposition of contaminants on the membrane surface. The emissivity measured at low concentration of $333 \mathrm{ppm}$ was found to be much lesser than that obtained higher feed concentrations of 1833 ppm and 3333 ppm. This was consistent with previous reports that emissivity increases with surface roughness. The increased surface roughness due to deposition of aluminum oxide nanoparticles results in increased emissivity. Additionally the phenomenon of metallic materials having lower emissivity in comparison with non-metallic materials at wavelengths above the plasma wavelength of the metallic component was leveraged to distinguish metallic aluminum particles from non-metallic aluminum oxide particles. This represents an avenue for future exploration to further ascertain the usefulness of this approach for various compositional characterizations of membrane foulants. An important advantage of the proposed IRT method for fouling characterization is the cost factor. The IRT system is relatively inexpensive and easier to use compared to the SEM or atomic force microscope (AFM). However, the use of the IRT method in conjunction with existing techniques will provide better understanding of the mechanism of fouling in membrane studies. The capabilities of the infrared thermography technique for fouling characterization have not been fully investigated and this work represents an initial assessment on the potentials of this emerging non-invasive membrane fouling characterization technique.

\section{ACKNOWLEDGEMENT}

The authors acknowledge funding from US department of energy (DOE). We thank Chenguang Sheng for his assistance with SEM-EDX analysis. 


\section{REFERENCES}

[1] A.P. Mairal, A.R. Greenberg, W.B. Krantz, Investigation of membrane fouling and cleaning using ultrasonic time-domain reflectometry, Desalination. 130 (2000) 45-60.

[2] D.Y. Kim, M.H. Lee, S. Lee, J.H. Kim, D.R. Yang, Online estimation of fouling development for SWRO system using real data, Desalination. 247 (2009) 200-209.

[3] M. Mulder, Basic Principles of Membrane Technology Second Edition, 1996. http://linkinghub.elsevier.com/retrieve/pii/037673889285058Qlnhttp://scholar.google.com/scholar?hl=en \&btnG=Search\&q=intitle:basic+principles+of+membrane+technology\# $1 \backslash$ nhttp://scholar.google.com/sch olar?hl=en\&btnG=Search\&q=intitle:Basic+principles+of+membrane+technology\#1 .

[4] J.C. Schippers, J. Verdouw, The modified fouling index, a method of determining the fouling characteristics of water, Desalination. 32 (1980) 137-148.

[5] F. Meng, B. Liao, S. Liang, F. Yang, H. Zhang, L. Song, Morphological visualization, componential characterization and microbiological identification of membrane fouling in membrane bioreactors (MBRs), J. Memb. Sci. 361 (2010) 1-14.

[6] P. Le-Clech, Y. Marselina, Y. Ye, R.M. Stuetz, V. Chen, Visualisation of polysaccharide fouling on microporous membrane using different characterisation techniques, J. Memb. Sci. 290 (2007) 36-45.

[7] H. Choi, K. Zhang, D.D. Dionysiou, D.B. Oerther, G.A. Sorial, Effect of permeate flux and tangential flow on membrane fouling for wastewater treatment, Sep. Purif. Technol. 45 (2005) 68-78.

[8] J. Wang, F. Dismer, J. Hubbuch, M. Ulbricht, Detailed analysis of membrane adsorber pore structure and protein binding by advanced microscopy, J. Memb. Sci. 320 (2008) 456-467.

[9] J. Lee, W.Y. Ahn, C.H. Lee, Comparison of the filtration characteristics between attached and suspended growth microorganisms in submerged membrane bioreactor, Water Res. 35 (2001) 2435-2445.

[10] B. Fan, X. Huang, Characteristics of a self-forming dynamic membrane coupled with a bioreactor for municipal wastewater treatment, Environ. Sci. Technol. 36 (2002) 5245-5251.

[11] J. yu Tian, Z. lin Chen, Y. ling Yang, H. Liang, J. Nan, G. bai Li, Consecutive chemical cleaning of fouled PVC membrane using $\mathrm{NaOH}$ and ethanol during ultrafiltration of river water, Water Res. 44 (2010) 59-68.

[12] M. Vellvehi, X. Perpiñà, G.L. Lauro, F. Perillo, X. Jordà, Irradiance-based emissivity correction in infrared thermography for electronic applications, Rev. Sci. Instrum. 82 (2011).

[13] S. Huth, O. Breitenstein, A. Huber, D. Dantz, U. Lambert, F. Altmann, Lock-In IR-Thermography - A Novel Tool for Material and Device Characterization, Solid State Phenom. 82-84 (2002) 741-746.

[14] M.S. Jadin, S. Taib, Recent progress in diagnosing the reliability of electrical equipment by using infrared thermography, Infrared Phys. Technol. 55 (2012) 236-245. doi:10.1016/j.infrared.2012.03.002.

[15] Y. Cao, X.M. Gu, Q. Jin, Infrared technology in the fault diagnosis of substation equipment, in: 2008 China Int. Conf. Electr. Distrib. CICED 2008, 2008. 
[16] M.P. Luong, Fatigue limit evaluation of metals using an infrared thermographic technique, Mech. Mater. 28 (1998) 155-163.

[17] M.L. Pastor, X. Balandraud, M. Grédiac, J.L. Robert, Applying infrared thermography to study the heating of 2024-T3 aluminium specimens under fatigue loading, Infrared Phys. Technol. 51 (2008) 505515.

[18] L. Jiang, H. Wang, P.K. Liaw, C.R. Brooks, D.L. Klarstrom, Characterization of the temperature evolution during high-cycle fatigue of the ULTIMET superalloy: Experiment and theoretical modeling, Metall. Mater. Trans. A. 32 (2001) 2279-2296.

[19] C. Badulescu, M. Grédiac, H. Haddadi, J.D. Mathias, X. Balandraud, H.S. Tran, Applying the grid method and infrared thermography to investigate plastic deformation in aluminium multicrystal, Mech. Mater. 43 (2011) 36-53.

[20] B. Venkataraman, B. Rai, C.K. Mukhopadhyay, T. Jayakumar, Correlation of infrared thermographic patterns and acoustic emission signals with tensile deformation and fracture processes, Rev. Prog. Quant. Nondestruct. Eval. Vols 20a 20b. 557 (2001) 1443-1450.

[21] J. Kumar, S. Baby, V. Kumar, Thermographic studies on IMI-834 titanium alloy during tensile loading, Mater. Sci. Eng. A. 496 (2008) 303-307.

[22] H. Ait-Amokhtar, C. Fressengeas, S. Boudrahem, The dynamics of Portevin-Le Chatelier bands in an AlMg alloy from infrared thermography, Mater. Sci. Eng. A. 488 (2008) 540-546.

[23] E. Grinzato, C. Bressan, S. Marinetti, P.G. Bison, C. Bonacina, Monitoring of the Scrovegni Chapel by IR thermography: Giotto at infrared, Infrared Phys. Technol. 43 (2002) 165-169.

[24] M.R. Clark, D.M. McCann, M.C. Forde, Application of infrared thermography to the non-destructive testing of concrete and masonry bridges, in: NDT E Int., 2003: pp. 265-275. doi:10.1016/S09638695(02)00060-9.

[25] C. Meola, Infrared thermography of masonry structures, Infrared Phys. Technol. 49 (2007) $228-233$. doi:10.1016/j.infrared.2006.06.010.

[26] S. Bagavathiappan, B.B. Lahiri, T. Saravanan, J. Philip, T. Jayakumar, Infrared thermography for condition monitoring - A review, Infrared Phys. Technol. 60 (2013) 35-55.

[27] C. Meola, G.M. Carlomagno, A. Squillace, G. Giorleo, The use of infrared thermography for nondestructive evaluation of joints, Infrared Phys. Technol. 46 (2004) 93-99. doi:10.1016/j.infrared.2004.03.013.

[28] R. Kafieh, T. Lotfi, R. Amirfattahi, Automatic detection of defects on polyethylene pipe welding using thermal infrared imaging, Infrared Phys. Technol. 54 (2011) 317-325.

[29] U. Sreedhar, C.V. Krishnamurthy, K. Balasubramaniam, V.D. Raghupathy, S. Ravisankar, Automatic defect identification using thermal image analysis for online weld quality monitoring, J. Mater. Process. Technol. 212 (2012) 1557-1566. doi:10.1016/j.jmatprotec.2012.03.002. 
[30] S. Marinetti, P.G. Cesaratto, Emissivity estimation for accurate quantitative thermography, NDT E Int. 51 (2012) 127-134. doi:10.1016/j.ndteint.2012.06.001.

[31] M.M. Awad, Impact of Flow velocity on Surface Particulate Fouling - Theoretical Approach, 8 (2012).

[32] C.F. Bohren, E.E. Clothiaux, Fundamentals of Atmospheric Radiation: An Introduction with 400 Problems, Wiley-VCH Verlag GmbH, 2008. 


\section{Figures and Table}

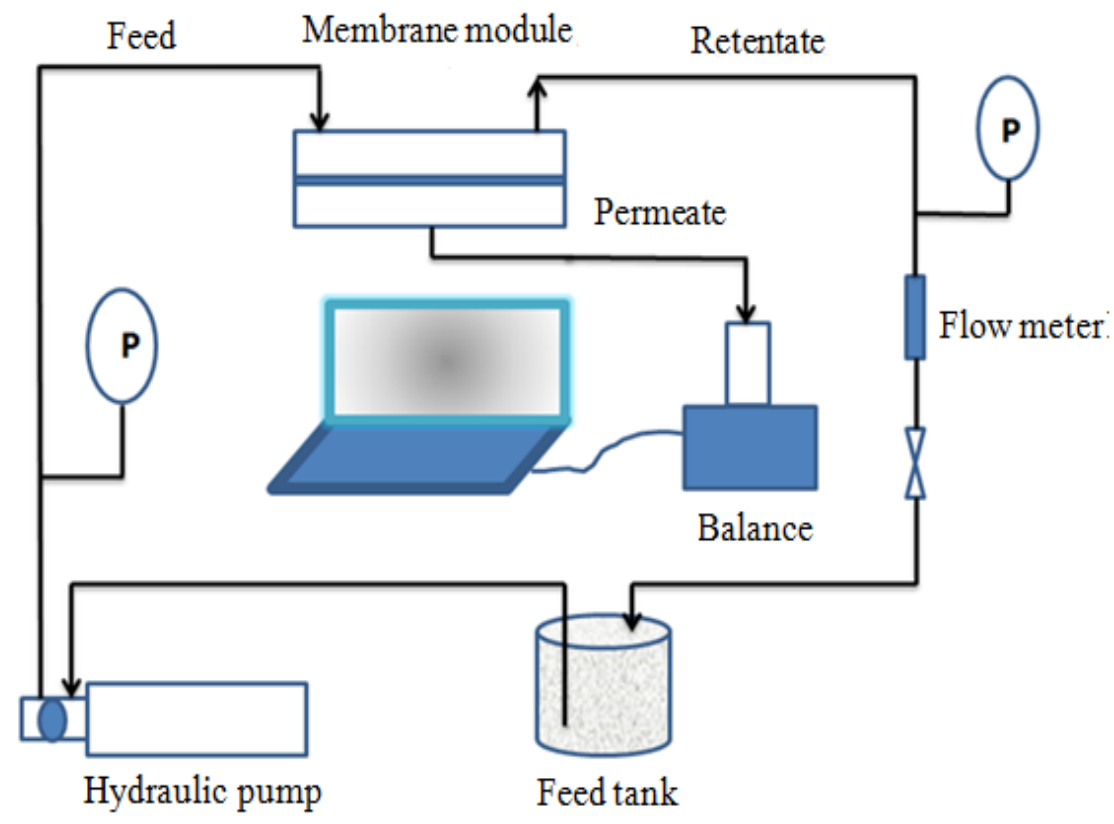

Fig. 1: Schematic of the UF membrane filtration system

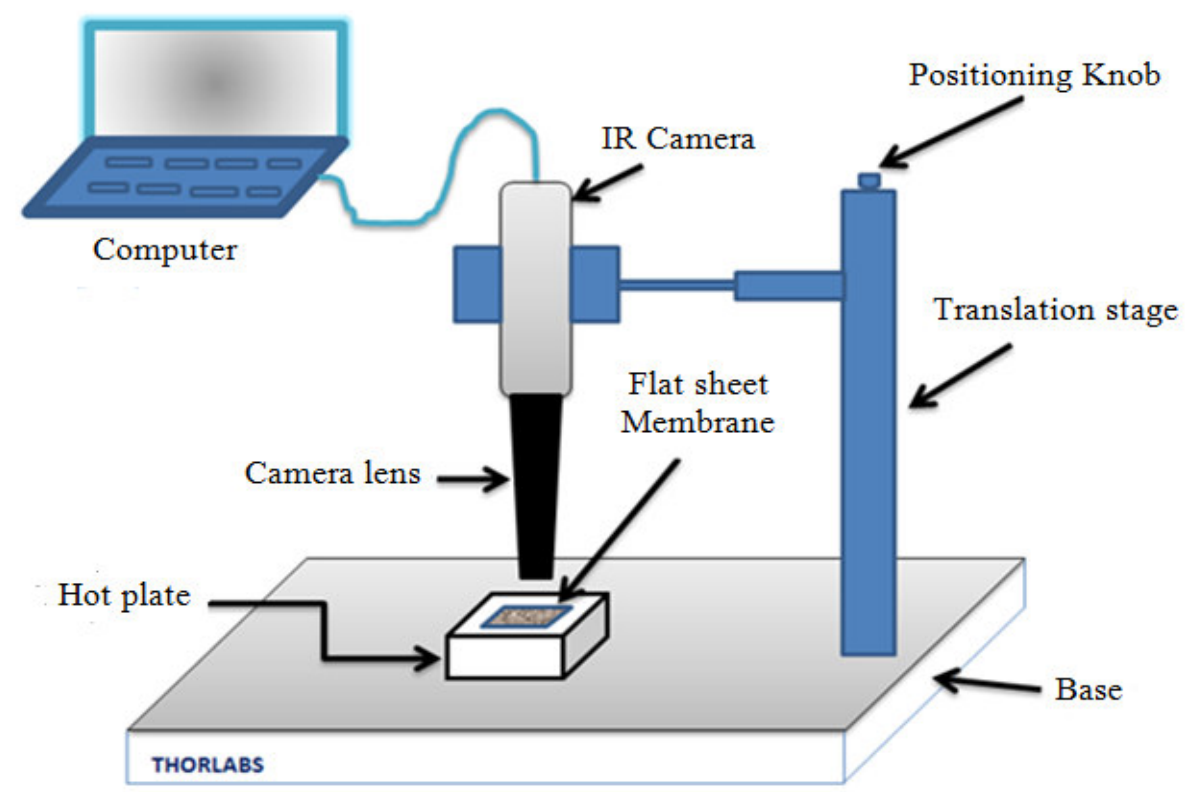

Fig S4: Schematic of the infrared thermography set-up for membrane fouling characterization

Table 1: Operating conditions for the fouling experiment

\begin{tabular}{l|l} 
Parameters & Value
\end{tabular}




\begin{tabular}{|l|l|}
\hline Feed types & $\begin{array}{l}\text { Aluminum Oxide + } \\
\text { Water, } \\
\text { Aluminum + Water }\end{array}$ \\
\hline Feed Concentration & $\begin{array}{l}333, \quad 1833 \quad \& \quad 3333 \\
\text { ppm }\end{array}$ \\
\hline Pressure & $20 \mathrm{psi}$ \\
\hline Temperature & $23 \pm 2^{\circ} \mathrm{C}$ \\
\hline $\begin{array}{l}\text { Operating frequency } \\
\text { of Pump }\end{array}$ & $25 \mathrm{~Hz}$ \\
\hline Speed of stirrer & $300 \pm 10$ RPM OSMONICS \\
\hline $\begin{array}{l}\text { Membrane type } \\
\mathrm{GE} \\
\mathrm{PVDF} \\
\mathrm{membrane}\end{array}$ \\
\hline $\begin{array}{l}\text { Effective membrane } \\
\text { area }\end{array}$ & $42 \mathrm{~cm}^{2}$ \\
\hline $\begin{array}{l}\text { Duration of } \\
\text { experiment }\end{array}$ & $240 \mathrm{minutes}^{2}$ \\
\hline
\end{tabular}

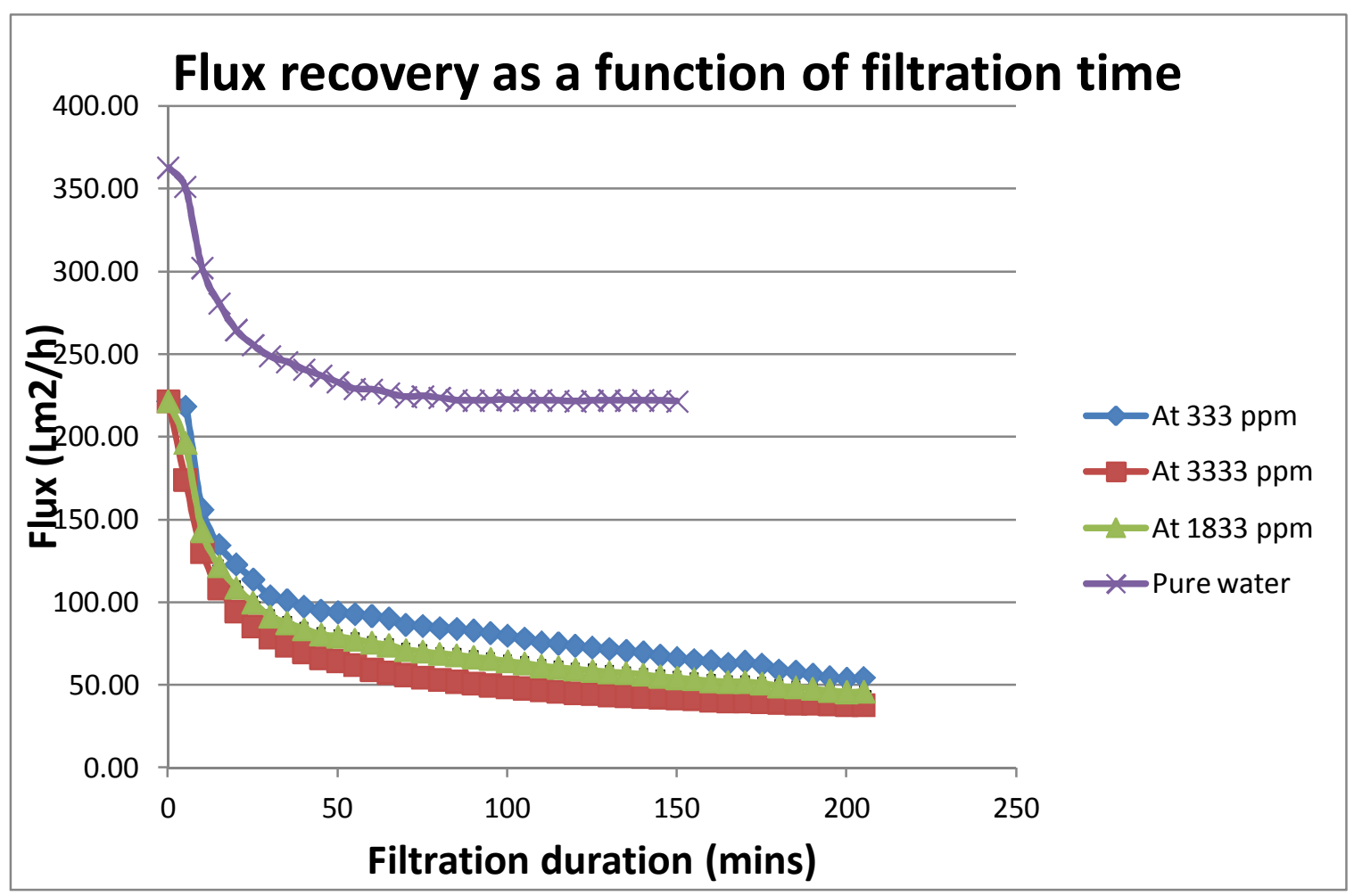

(a) 


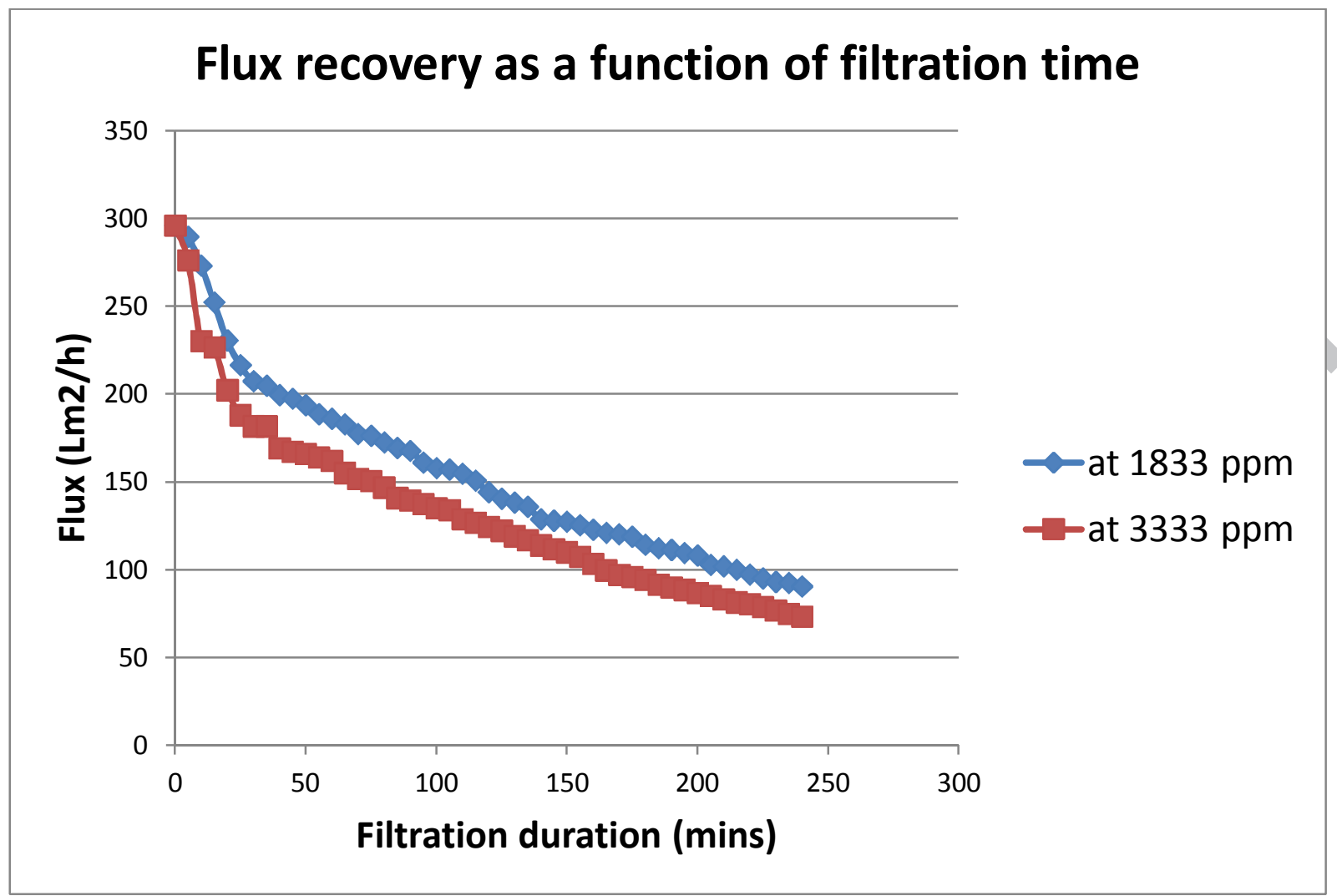

(b)

Fig 2: Permeate flux versus filtration duration of the fouling experiments for (a) aluminum oxide, and (b) aluminum particles in deionized water 


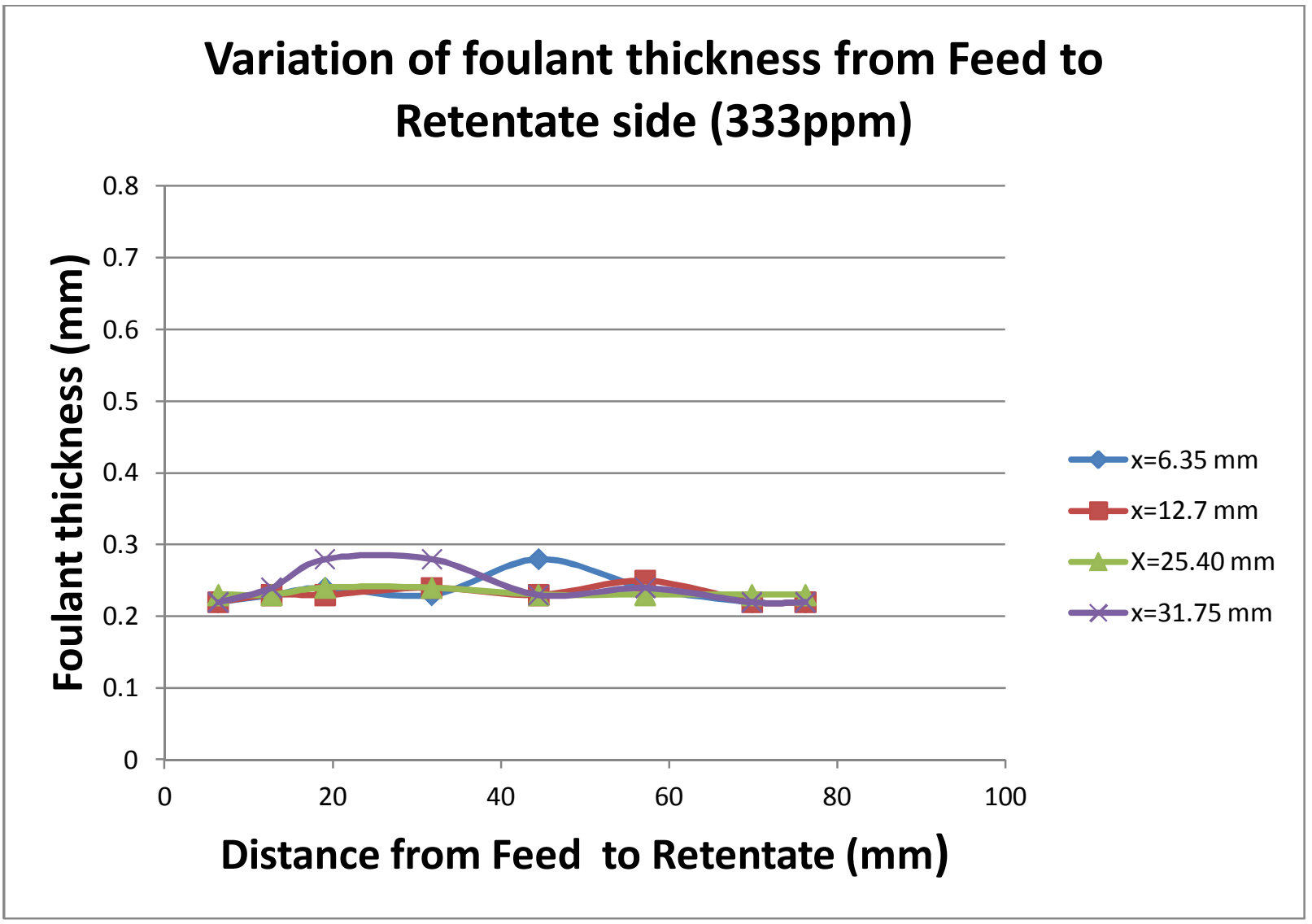

(3a)

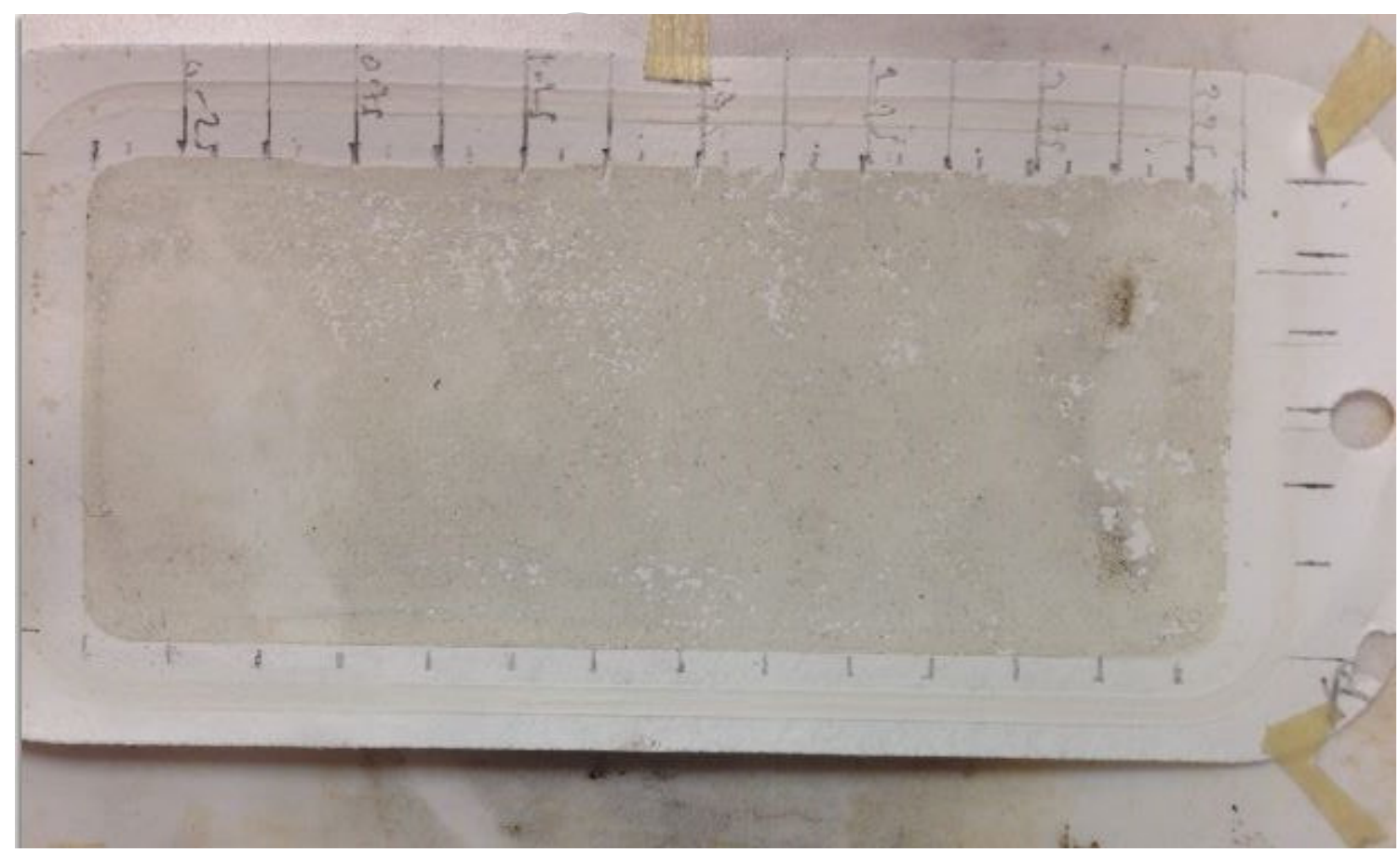

Inserted in figure (3a) 


\section{Variation of thickness from Feed to Retentate side (3333ppm)}

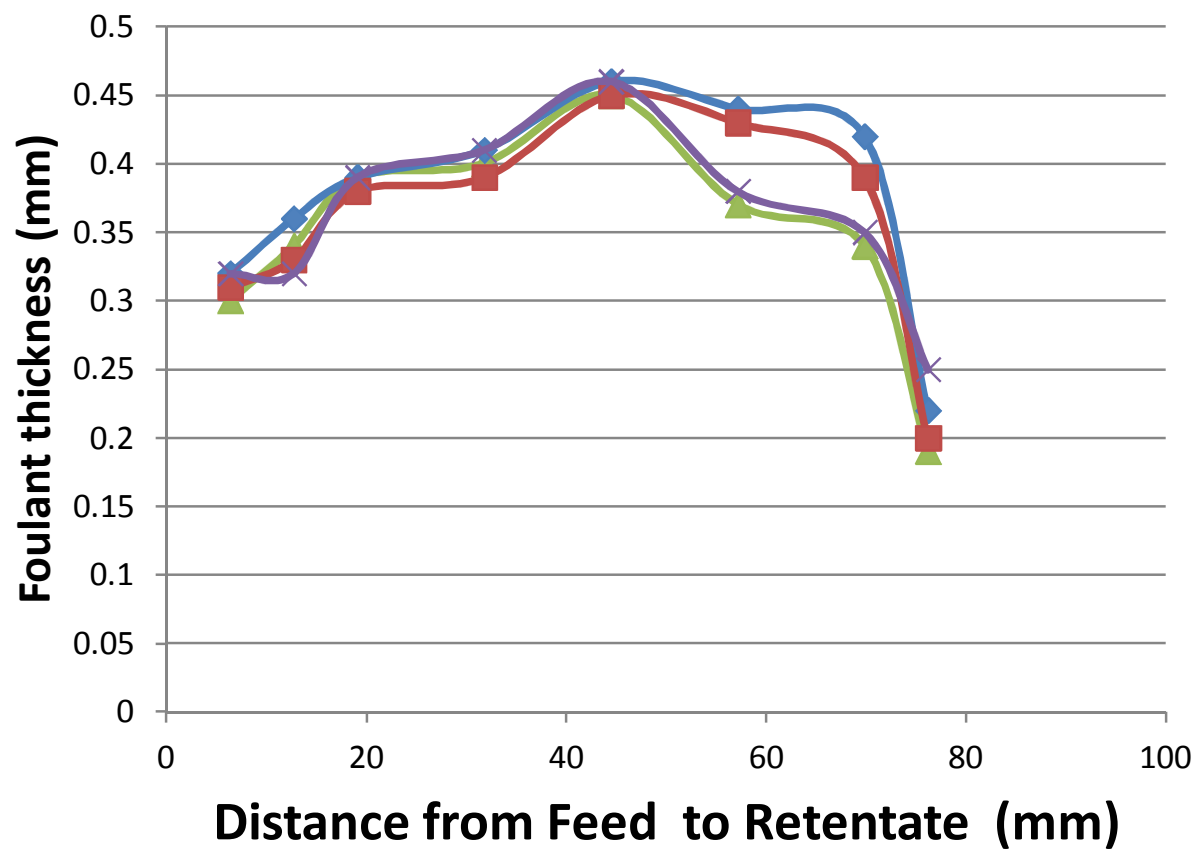

$-x=6.35 \mathrm{~mm}$

$\smile x=12.7 \mathrm{~mm}$

$-x=25.4 \mathrm{~mm}$

$\leftarrow x=31.75 \mathrm{~mm}$

(3b)

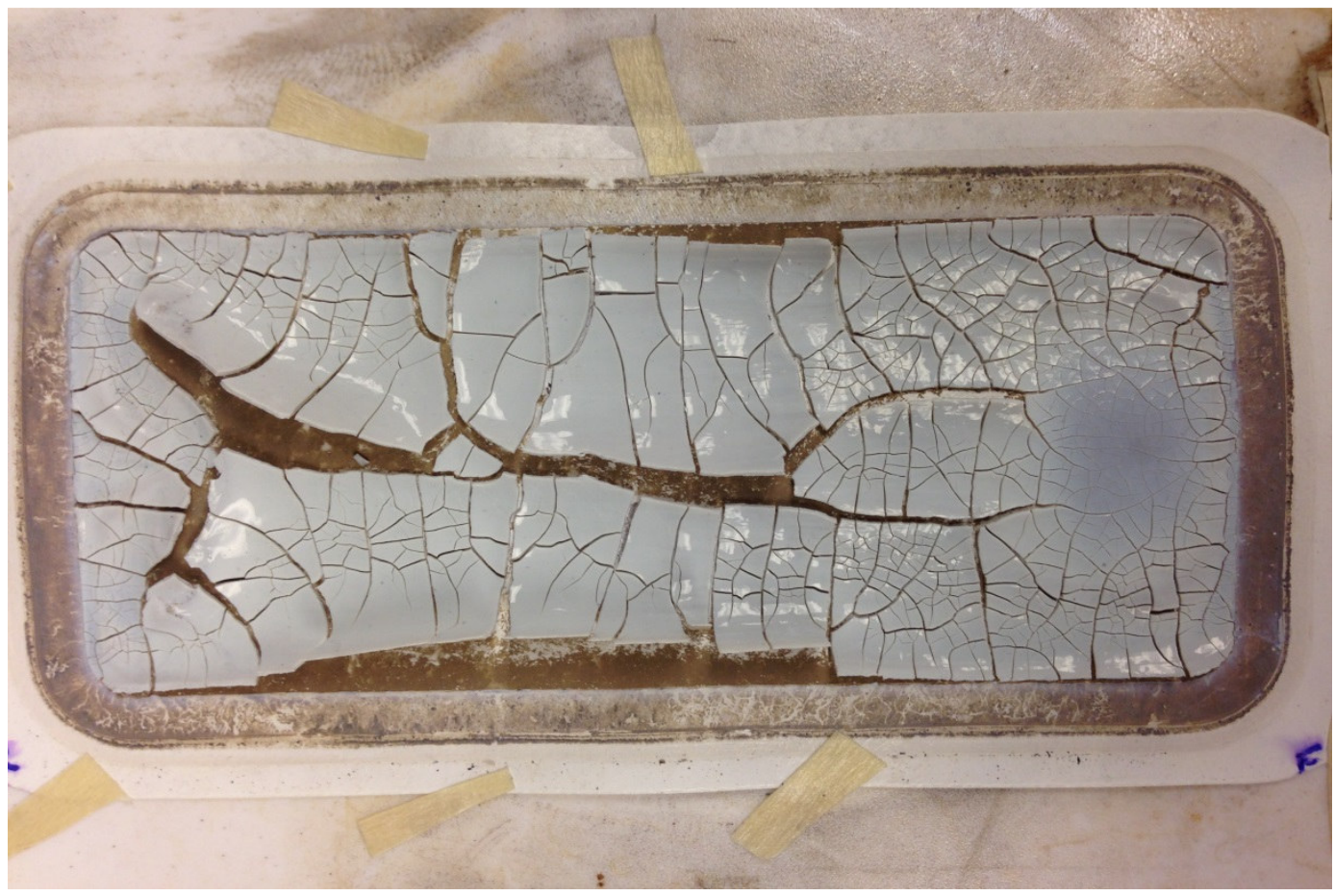

Inserted in figure (3b)

Fig 3: Line plot showing variation of foulant thickness from feed to retentate side for fouled membranes corresponding to (a) $333 \mathrm{ppm}$ and (b) $3333 \mathrm{ppm}$ feed concentrations of aluminum oxide. The insert shows the pictorial views of the fouled membranes at the corresponding feed concentrations 